\title{
Ruminant chronophysiological management: an emerging bioscience
}

This article was published in the following Dove Press journal:

Open Access Animal Physiology

25 August 2011

Number of times this article has been viewed

\begin{abstract}
Akbar Nikkhah
Department of Animal Sciences, Faculty of Agricultural Sciences, University of Zanjan, Zanjan, Iran
\end{abstract}

Correspondence: Akbar Nikkhah Department of Animal Sciences, Faculty of Agricultural Sciences, The University of Zanjan, Zanjan 3 I 3-45 I 95, Iran Tel +9824 I5।5280।

Fax +9824 I528 3202

Email nikkhah@znu.ac.ir
Abstract: The objective of this paper is to introduce, discuss, and delineate an emerging bioscience known as ruminant chronophysiological management. Most recent research discoveries have promised physiological innovations in laboratory animals, humans, and livestock. Lactating ruminants have high intake and production levels above maintenance, and thus are exceptional models for studying evolutionary nutrition and physiology. The evolution of ruminant animals has led to specialized behaviors that involve mainly overnight rumination and primary daytime (sunrise and sunset) grazing and eating. Consequently, eating activity, rumen ecology, postrumen nutrient assimilation, and peripheral nutrient metabolism have developed unique diurnal and nocturnal rhythms. These physiological rhythms are known as circadian rhythms that lead animal endocrinology and metabolism. Most recent findings demonstrate that altering feeding timing alters postprandial patterns of feed intake, rumen fermentation, and peripheral metabolism in both intensively housed and grazing lactating cows. Evening instead of morning feeding has improved milk and milk energy production. These demonstrations contribute to creating an evolutionary bioscience that links animal nutritional management and physiology to chronobiology. The emerging bioscience of "ruminant chronophysiological management" is the incorporation of chronophysiology into livestock management practices. Different species will have their own special response to altered chronophysiological management. Such postmodern management strategies will therefore be an interface of ruminant, nonruminant, and human ecologies.

Keywords: animal agriculture, bioscience, chronology, evolution, management, ruminant

\section{Introduction}

For maximum efficiency, the timing of nutrient delivery to the rumen, splanchnic tissues, and the periphery should be synchronized with endogenous rhythms in body metabolism. Diurnal rhythms in body metabolism are shown in endogenous and exogenous rhythms of blood levels of metabolites and hormones. Endogenous rhythms are regulated internally by the suprachiasmatic nuclei of the hypothalamus and externally by photoperiod and feeding time. ${ }^{1}$ For instance, blood glucose in humans has endogenous rhythmicity. ${ }^{2}$ In contrast, exogenous rhythms are controlled by external agents. Blood urea is mostly responsive to feeding and digestive function, and thus, is exogenously regulated. ${ }^{3}$ Humans metabolize glucose more effectively in the morning than in the evening. ${ }^{4}$ This is because glucose tolerance and insulin sensitivity decrease as the day progresses and the evening begins. ${ }^{2}$ Such knowledge, for instance, would lead to a suggestion to avoid large evening meals to reduce the risks of type 2 diabetes and related cardiovascular complications. Incorporation of chronophysiology into 
livestock management may lead to the development of recommendations that could improve animal production, health, and economics. The primary objective of this perspective review is to offer insight and discuss the most recent research evidence on how timing of feeding/eating alters postprandial animal physiology. In so doing, the emerging bioscience of "animal chronophysiological management" is introduced and delineated.

\section{Research findings}

The lactating cow is an exceptional mammal with uniquely high levels of feed intake and milk production (eg, $>50-60 \mathrm{~kg}$ milk/day, as high as $6 \times$ maintenance). Any chronobiological mediation of the rumen and intermediary metabolism will have an enormous impact on milk secretion and tissue deposition. It is important to determine if and to what extent feeding time can alter such diurnal patterns in the rumen and ruminant metabolism. Such knowledge will indicate the time of day when nutrients can be assimilated more efficiently for both productivity and body energy expenditure. Evening rather than morning feeding can improve the performance of beef cattle. ${ }^{5-8}$ Ruminants have evolved to ruminate mostly overnight, when the rumen develops a greater fermentation capacity and volume, compared with daytime. ${ }^{9}$ Feeding ruminants in the evening could thus significantly alter postfeeding fermentation patterns. A lack of knowledge has existed as to whether changing the feeding time, especially in animals fed once daily, can alter postfeeding patterns of feed intake. As such, it was unknown if feeding time can alter postfeeding patterns in rumen fermentation and peripheral blood metabolites and hormones in lactating cows. New insights into the postfeeding patterns of ingestion, digestion, and metabolism will help to elucidate the mechanisms whereby feeding time mediates productive responses in ruminants. In humans and rats, for example, regulation of glucose metabolism and insulin sensitivity has been shown to depend heavily on time of day. ${ }^{2,4}$

Nikkhah et $\mathrm{al}^{9,10}$ demonstrated that feed delivery at 2100 hours instead of 0900 hours in tie-stall-housed lactating cows under no heat stress increased feed intake within 3 hours after feeding by about $2.4 \mathrm{~kg}$ of dry matter (Figure 1). The increased feed intake shortly postfeeding was associated with comparable dry matter intake in one study, ${ }^{10}$ whereas in another study it increased dry matter intake in primiparous and not in multiparous cows. ${ }^{11}$ Feeding at 2100 hours increased rumen volatile fatty acids concentrations at 4-6 hours postfeeding without compromising rumen function, and increased rumen ammonia at 2 hours postfeeding, compared with feeding at 0900 hours (Figure 2). Urinary excretion of purine derivatives (allantoin and uric acid) was not significantly affected by feeding time, suggesting that microbial protein synthesis was similar for evening-fed and morning-fed cows. ${ }^{12}$ Peripheral blood betahydroxybutyrate and L-lactate at 2 and 4 hours postfeeding were higher in cows fed at 2100 hours than in cows fed at 0900 hours (Figure 3). ${ }^{11,13}$ Peripheral blood L-lactate across sampling times was higher in cows fed at 2100 hours versus 0900 hours. ${ }^{10}$ Blood beta-hydroxybutyrate across sampling times was similar between treatments. Blood urea rose at 2 hours postfeeding in both 2100 hour-fed and 0900 hour-fed cows. ${ }^{10}$ In another lactating cow study, ${ }^{11}$ the postfeeding rise in blood urea occurred in the 0900 hour-fed cows but not in the 2100 hour-fed cows. Postprandial peripheral glucose

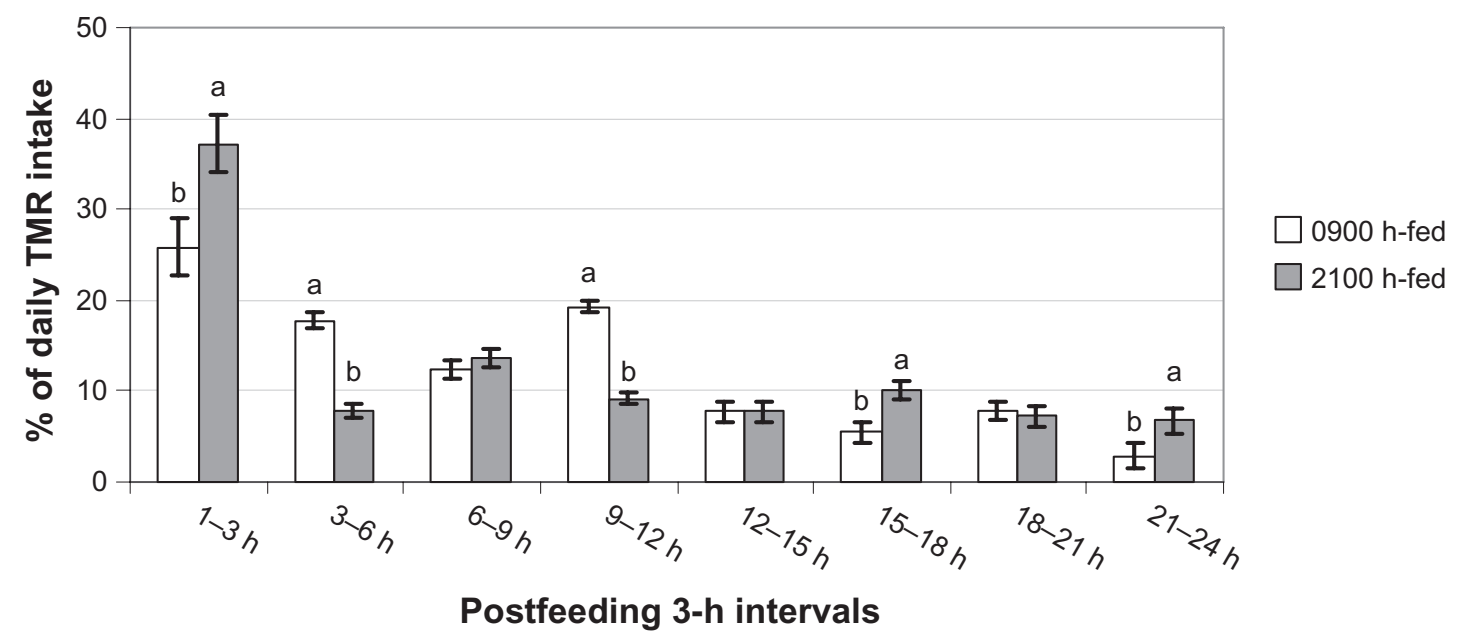

Figure I Postfeeding patterns of feed intake in cows fed at either 0900 hours or 2100 hours.

Note: Within each 3-hour period, bars with different superscripts differ at $P<0.05$. 910

Abbreviation: TMR, total mixed ration. 


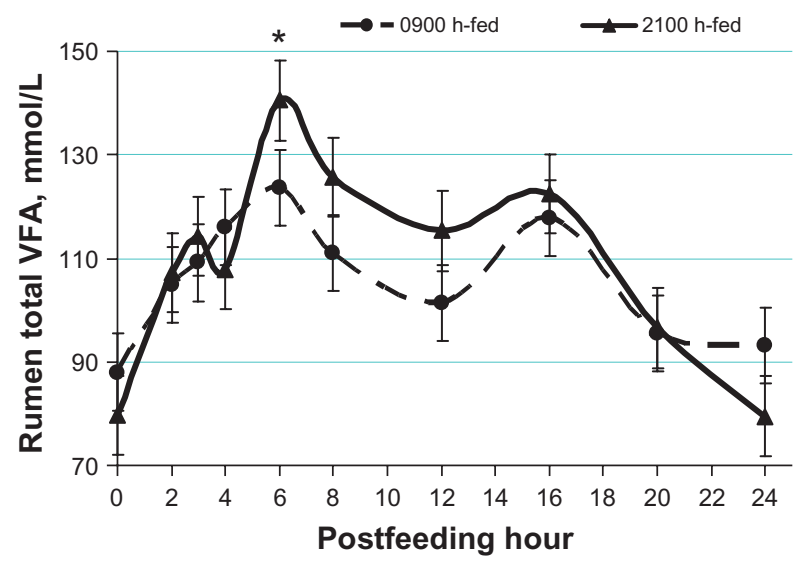

Figure 2 Postfeeding patterns of rumen total volatile fatty acids (VFA) concentrations in cows fed either at 0900 hours or at 2100 hours.

Note: Within each hour, $* P<0.05 .^{12}$

Abbreviation: VFA, volatile fatty acids.

and insulin rhythms also showed significant responses to altered timing of feeding. ${ }^{11,14}$ These data establish a chronological nature for ruminant physiology and metabolism that is regulated by timing of feeding and eating. The altered postprandial rhythms of rumen fermentation and peripheral blood metabolites are closely linked to altered feed intake patterns in evening-fed cows. Fundamentally, altering time of feeding alters eating rate and the amount of food consumed shortly postfeeding. It is suggested that animal psychology is also involved. Some cows may anticipate feeding times better than others. Anticipating feed delivery may lead cows to crave for fresh feed and thus increase their eating rate for a certain period after feed delivery. ${ }^{9-11}$ Cows may have more accurately anticipated evening feed delivery compared with morning feed delivery.

Feeding at 2100 hours instead of 0900 hours intensified rumen fermentation within 4-6 hours postfeeding, increased

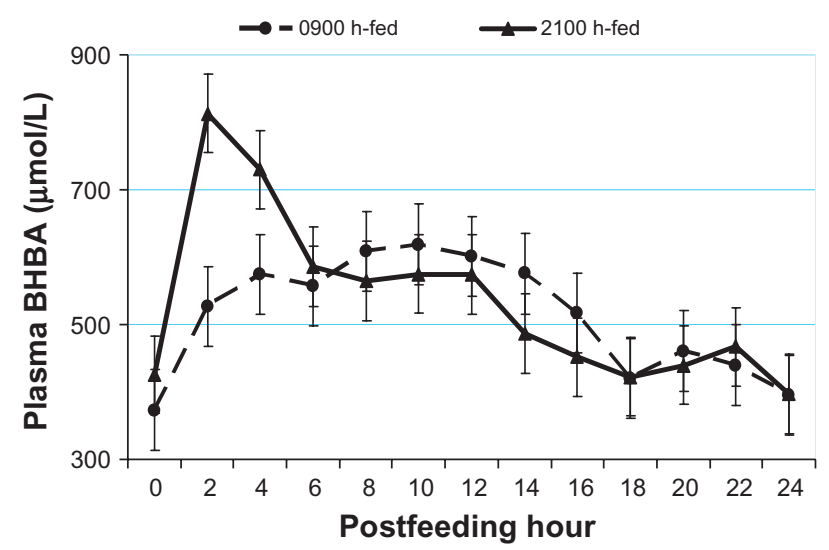

Figure 3 Postprandial patterns of plasma $\beta$-hydroxybutyrate (BHBA) in cows fed either at 0900 hours or 2100 hours.

Note: For 2-h and 4-h postfeeding, treatments differ at $P<0.05 .^{13}$ rumen volume, but did not change rumen fluid outflow rate or rumen fluid and solid retention times. ${ }^{9,11,15}$ Dry matter intake and rumen solid outflow rate was higher in 2100 hour-fed than in 0900 hour-fed primiparous cows. ${ }^{9}$ The increased eating rate within 3 hours of feeding in all cows and the increased daily dry matter intake and rumen solids outflow rate in primiparous cows by evening feeding is consistent with increased rumen fermentation, enlarged rumen volume, and unchanged rumen content retention time. Feeding at 2100 versus 0900 hours improved dry matter, nitrogen, neutral detergent fiber, and acid detergent fiber total tract digestibility. The majority of fiber digestion occurs in the rumen. Thus, the improved total tract nutrient and fiber digestibility was most likely and mostly due to increased ruminal fiber digestion. This agrees with the increased rumen fermentation of the evening-fed cows. Feeding at 2100 hours did not affect total proportions of short, medium, or long chain fatty acids in milk. ${ }^{12}$ This suggested that daily yield of fatty acids with implications for human health (eg, monounsaturated fatty acids and cis-9, trans-11 conjugated linoleic acid) was enhanced by evening feeding, since milk fat yield was increased by evening versus morning feeding (1.22 versus $1.05 \mathrm{~kg} /$ day; 1.06 versus $0.9 \mathrm{~kg} /$ day). ${ }^{10,11}$ The main reasons for the increased milk fat and energy output included the increased total tract nutrient digestibility and peripheral availability of milk precursors (beta-hydroxybutyrate, L-lactate, and probably acetate). ${ }^{10,11,13,14}$ Consequently, fecal and urinary nitrogen losses were reduced in favor of body nitrogen retention by feeding at 2100 hours. ${ }^{12}$

Feeding at 2100 hours instead of 0900 hours altered diurnal patterns of feed intake. ${ }^{9}$ In so doing, feeding at 2100 hours increased peripheral availability of milk precursors, including rumen volatile fatty acids and blood metabolites. The altered postfeeding patterns of rumen and blood metabolites included a marked increase in rumen concentrations of volatile fatty acids at 4-6 hours postfeeding and that of blood metabolites at $2-4$ hours postfeeding. These are linked to increased eating rate shortly postfeeding in evening-fed versus morning-fed cows. ${ }^{10,11,14}$ Increased nocturnal rumen fermentation has been shown in grazing lactating cows as well. ${ }^{16}$ As a result of improved nutrient digestibility and peripheral nutrient availability, milk fat yield was increased by feeding at 2100 hours ( 1.22 versus $1.05 \mathrm{~kg}$ /day, and 1.06 versus $0.9 \mathrm{~kg} /$ day). ${ }^{10,11}$ In addition, nitrogen retention was enhanced. Reduced nitrogen excretion via feces and urine by evening instead of morning feeding involves environmental implications. Altogether, feeding time provides a suitable model to study the evolutionary basis of feed intake 
regulation and chronophysiological management of livestock in postmodern animal agriculture. ${ }^{17}$

\section{Conclusion}

Evolution introduces new insights into livestock chronophysiology and management. Recent research discoveries have uncovered the evolutionary regulation of feed intake, rumen ecology, and peripheral metabolism in high-producing dairy ruminants. Evening instead of morning feeding of the same diets has altered postprandial patterns of nutrient intake, rumen fermentation, and peripheral metabolites and hormones. As a result, evening versus morning feeding has improved milk fat and energy yield, and reduced urinary and fecal nitrogen excretion. These demonstrations establish a chronological nature for ruminant physiology. Such chronophysiological principles should be incorporated into livestock management in the postmodern era. These contribute to the emergence of the new bioscience of "ruminant chronophysiological management." This bioscience will interface animal longevity and health, a safe and secure food supply, and quality of the environment.

\section{Acknowledgments}

Nature, the environment, the Ministry of Science, Research and Technology, and University of Zanjan, Iran, are especially acknowledged for inspiring and supporting the author's programs of optimizing science education in the new millennium.

\section{Disclosure}

The author reports no conflicts of interest in this work.

\section{References}

1. Sehgal A. Molecular Biology of Circadian Rhythms. Hoboken, NJ: John Wiley and Sons Inc; 2004.

2. la Fleur SE, Kalsbeek A, Wortel J, Fekkes MI, Buijs RM. A daily rhythm in glucose tolerance: A role for the suprachiasmatic nucleus. Diabetes. 2001;50:1237-1243.
3. Piccione G, Caola G. Review: Biological rhythms in livestock. $J$ Vet Sci. 2002;3:145-157.

4. Van Cauter E, Biackman J, Roland D, Spire J-P, Refetoff S, Polonsky KS. Modulation of glucose regulation and insulin secretion by circadian rhythmicity and sleep. J Clin Invest. 1991;88:934-942.

5. Kennedy AD, Bergen RD, Lawson TJ, Small JA, Veira DM. Effects of evening feeding and extended photoperiod on growth, feed efficiency, live animal carcass traits and plasma prolactin of beef heifers housed outdoors during two Manitoba winters. Can J Anim Sci. 2004;84:491-500.

6. Pritchard RH, Knutsen JS. Feeding Frequency and Timing, Intake by Feedlot Cattle. Oklahoma Agric. Exp. Stn., Oklahoma State University, Stillwater; 1995; P-942: 162-166.

7. Schwartzkopf-Genswein KS, Beauchemin KA, McAllister TA, Gibb DJ, Streeter M, Kennedy AD. Effect of feed delivery fluctuations and feeding time on ruminal acidosis, growth performance, and feeding behavior of feedlot cattle. J Anim Sci. 2004;82:3357-3365.

8. Small JA, Kennedy AD, Veira DM, McCaughey WP, Ward DR. Time of feeding and growth promotant effects on the winter growth performance and carcass traits of steers. Can J Anim Sci. 2004;84:133-144.

9. Nikkhah A, Plaizier JC, Furedi CJ, Kennedy AD. Time of feeding: A determinant of post feeding patterns in feed intake of lactating cows. J Dairy Sci. 2007:90 Suppl 1:559.

10. Nikkhah A, Furedi CJ, Kennedy AD, Crow G, Plaizier JC. Effects of feed delivery time on feed intake, rumen fermentation, blood metabolites and productivity of lactating cows. J Dairy Sci. 2008;91:1-12.

11. Nikkhah A, Furedi CJ, Kennedy AD, Scott SL, Crow G, Wittenberg KM. Feed delivery at $2100 \mathrm{~h}$ vs $0900 \mathrm{~h}$ for lactating dairy cows. Can J Anim Sci. 2011;91:113-122.

12. Nikkhah A. Postprandial rhythms of circulating urea in lactating dairy cows: feeding timing and diet effects. Biol Rhythm Res. 2011. In press.

13. Nikkhah A, Plaizier JC, Furedi CJ, Kennedy AD. Response in diurnal variation of circulating blood metabolites to nocturnal vs diurnal provision of fresh feed in lactating cows. J Anim Sci. 2006; 84 Suppl 1:111.

14. Furedi C, Kennedy AD, Nikkhah A, Plaizier JC. Glucose tolerance and diurnal variation of circulating insulin in evening and morning fed lactating cows. Adv Dairy Technol. 2006;18:356.

15. Nikkhah A, Plaizier JC, Kennedy AD. Rumen volume and passage kinetics depend on feeding time (0900 vs 2100 h). J Dairy Sci. 2011; 94E Suppl:374-375.

16. Taweel HZ, Tas BM, Dijkstra J, Tamminga S. Intake regulation and grazing behavior of dairy cows under continuous stocking. J Dairy Sci. 2004;87:3417-3427.

17. Nikkhah A. Bioscience of ruminant feed intake evolution: Feeding time models. Adv Biosci Biotechnol. 2011; In press.
Open Access Animal Physiology

\section{Publish your work in this journal}

Open Access Animal Physiology is an international, peer-reviewed, open access journal publishing original research, reports, reviews and commentaries on all areas of animal physiology. The manuscript management system is completely online and includes a very

\section{Dovepress}

quick and fair peer-review system. Visit http://www.dovepress.com/ testimonials.php to read real quotes from published authors. 